\title{
CES
}

COOPERATIVISMO E ECONOMÍA SOCIAL

Núm. 43 (2020-2021), páxs. 367-370

ISSN: 2660-6348

\section{RÉGIMEN JURÍDICO DE LAS SOCIEDADES COOPERATIVAS \\ CATALANAS, EDITORIAL ATELIER LIBROS JURÍDICOS, 2020 (DIR. ALFONSO SÁNCHEZ, R., COORD. ANDREU MARTÍ, M.M.), 637 PÁGINAS}

\author{
SARA Louredo CASAdo*
}

\footnotetext{
1 Investigadora Posdoctoral de la Xunta de Galicia. Profesora de Derecho Mercantil de la Universidad de Vigo. Visitante en el Centro de Investigação de Direito Privado de la Universidade de Lisboa. Dirección de correo electrónico: saralouredo@uvigo.es.

Dirección postal: Facultade de Ciencias Xurídicas e do Traballo, Universidade de Vigo, Campus As Lagoas-Marcosende s/n, CP36310, Vigo (Pontevedra).

El presente trabajo ha sido elaborado en el marco del Proyecto de Investigación financiado por el Ministerio de Ciencia, Innovación y Universidades: "El Derecho de la competencia y de la propiedad industrial: actualización, europeización y adaptación a la nueva economía" (2019-2022) Referencia: PGC2018-096084-B-I00.
} 

a obra que ahora reseñamos tiene como objeto de estudio la Ley 12/2015 de 9 de julio, de Cooperativas de Cataluña. Posee las virtudes de ser omnicomprensiva de esta legislación y de abordar su estudio desde una visión multidisciplinar gracias a las colaboraciones de numerosos profesores de Derecho Mercantil, así como de otras ramas del Derecho (Laboral, Procesal, Financiero) y de otras ramas del conocimiento (como la Economía Financiera). Además, no se limita, como podría parecer por su título, a la actual Ley sino que realiza en su primer capítulo un breve recorrido por la historia de las legislaciones catalanas en la materia, deteniéndose en la derogada por la norma actual, la Ley 18/2002 de 5 de julio.

En la propia presentación del libro se hace referencia a que, acerca de las cooperativas, "nos enfrentamos en definitiva a un nuevo reto. Si durante muchos años el interés del movimiento cooperativo se centró en la necesidad de proclamar unos principios identitarios de la forma social cooperativa (los cooperativos), ahora que ya se dispone de ellos y que son universalmente aceptados, lo que procede es la revisión del modo (formal y material) en que tales principios y sus valores han de tener reflejo en las legislaciones cooperativas de los distintos Estados de la comunidad internacional". A continuación, la directora realiza un símil de gran interés en relación a la vulgarización de las marcas, puesto que estamos tanto en ese caso como en el de la pérdida de operatividad y delimitación de los principios cooperativos ante la problemática e insegura deformación de la institución.

Es necesario reconocer este reto y también la consistente labor de la Directora y de la Coordinadora de esta obra de 637 páginas que en 21 capítulos aborda la constitución de la sociedad, la posición jurídica del socio, la estructura orgánica de la institución, la contabilidad y la disolución, los tipos de cooperativas de primer grado y su régimen laboral, procesal y fiscal, entre otros temas. La estructura sigue de cerca a la del Derecho Cooperativo Catalán del Prof. Borjabad del año 2005 y la profundidad del estudio se hace posible gracias a la participación de 20 autores.

Queremos detenernos en la idea inspiradora de la actual legislación: que la cooperativa es una asociación autónoma de personas que se han unido de forma voluntaria para satisfacer sus necesidades y aspiraciones económicas, sociales y culturales en común mediante una empresa de propiedad conjunta y de gestión democrática. Además, la aplicación de esta legislación se hace depender, en el art. 3 , de la realización de la actividad cooperativizada con los socios en Cataluña, sin perjuicio de sus actividades con terceras personas o de otras secundarias o accesorias. Sin embargo, a este criterio, ha de unirse el de que las cooperativas, federaciones y confederaciones reguladas han de tener su domicilio social en aquel municipio de Cataluña donde lleven a cabo sus actividades económicas y sociales 
principales. Esta relativa disparidad de criterios es comentada en el primer capítulo de la obra.

Finalmente, nos parece oportuno apuntar que, como la sociedad y, en consecuencia, el Derecho, son dinámicos y están sometidos a un cambio permanente, la legislación que el libro estudia, ha sido modificada por las Leyes 5/2017 y 7/2017 y por el Decreto-Ley 7/2021, todas ellas autonómicas. La primera es la Ley de 28 de marzo de medidas fiscales, administrativas, financieras y del sector público y de creación y regulación de los impuestos sobre grandes establecimientos comerciales. La segunda es del 2 de junio y ha regulado el régimen de las secciones de crédito de las cooperativas, abordado en el capítulo IX de la obra. Finalmente, el Decreto-Ley de 9 de febrero de 2021 trata las medidas extraordinarias en materia de cooperativas, empresas y entidades de la economía social como consecuencia de la crisis derivada de la Covid-19. Ésta es, de las tres, la única modificación posterior a la publicación del libro y, por tanto, no tratada por el mismo.

En conclusión, no podemos menos que felicitar a las coordinadoras y a los autores de la obra por elaborar un estudio riguroso y holístico de la materia cooperativa en Cataluña cuya utilidad no queda limitada a las cooperativas de esa comunidad, sino que apoyará cualquier estudio de la materia a nivel nacional o autonómico. La recomendación es, por tanto, que el lector "la tenga a mano" como obra de referencia. 